\title{
High-speed Data Long-line Transmission Modeling and Evaluation
}

\author{
Xiao $\mathrm{Li}^{1,2}$, Bowei Zhang ${ }^{2}$, Shaowei $\mathrm{Li}^{2}$, Chaojie Wang, ${ }^{1,2}$, Fanling Kong ${ }^{2}$ and Zhichao Xue \\ ${ }^{1}$ College of aerospace and materials engineering, National defense science and Technology University, Changsha, China 410073 \\ ${ }^{2}$ Key Laboratory of space physics, Beijing, China 100076
}

\begin{abstract}
In the field of aerospace, the amount of test data need to be transmitted is large, and the transmission is far. Especially when down sending the stored data, the code rate is as high as 200Mbps, and the data transmission distance is far, even up to several tens of meters. This paper presents a high-speed data long-line transmission modeling and evaluation method, for evaluation and design of high-speed data long-line transmission link, and setting up three test link based on the HOTLINK interface circuit. The data transmission under three kinds of situations were measured. After testing, the high-speed data longline transmission model is verified, and for the three links, the evaluation and classification are completed by the matrix evaluation method based on two indexes of link margin and bit error rate. The theoretical basis is established for the design of high-speed data long-line transmission link.
\end{abstract}

Keywords-high-speed,long-line,modeling

\section{INTRODUCTION}

In the field of aerospace, telemetry system is responsible for interpreting, recording and processing the parameters of measured object outside a certain distance, by feeling, acquiring and being transmitted to the receiving site through transmission media. The acquired data is used to analyze the tested object's working state and to guide the improvement of the subsequent design. In recent years, with the development of telemetry system technology, especially the emergence of solid state memory, the amount of test data is increasing, data transmission is more and more far, but RS-232, RS-485, and other bus [1] cannot meet the requirements, which are subject to the limit of the transmission speed. And then the high-speed data long-line transmission link is widely used, represented by HOTLINK (High Speed Optical Transceiver Link), LVDS (Low-Voltage Differential Signaling) interface [2]. Solid state memory [3] can completely record all kinds of state parameters when the space vehicle works. After the test, the working state parameters can be acquired by recovering and processing the recorded data. High-speed data long-line transmission link is usually used for ground test of solid state memory, especially when down sending the stored data, the code rate is up to $200 \mathrm{Mbps}$, at the same time, affected by the large test site, data transmission distance is long, even up to tens of meters, so the link will affect the reliability of the data transmission [4], and it's crucial to the system state detection results.

The hardware of the high-speed data long-line transmission link is composed of a transmitting circuit, a transmission channel and a receiving circuit. The transmitting circuit and the receiving circuit have mature interface standards. We can select the appropriate chip according to the working parameters of the system. In order to achieve reliable data transmission [5], on the one hand, the transmission channel need to meet the requirements of characteristic impedance, on the other hand to control the transmission distance, reduce the signal attenuation [6], so that the signal has a better integrity. However, the demand for controlling the transmission distance and the long line transmission is contradictory. At present, we take the general method of pre link built to know the real situation, and it has a long period and poor economic benefit, besides, problems are often appeared in the application process , such as usually affecting the system design, and even leading system solutions to significant repeated. In view of this problem, this paper proposes a method of modeling and evaluation for high-speed data long-line transmission, which is used to design and evaluate the high-speed data long-line transmission link, and then to reduce the risk of design and economic cost.

\section{The Modeling AND Evaluation Method OF High- SPEED DATA LONG-LINE TRANSMISSION}

\section{A. High-Speed Data Long-line Transmission Modeling}

The essence of whether a signal received correctly is whether the SNR meets the minimum requirements of the receiver. The SNR is higher, and the signal is more likely to be received correctly. The SNR is lower, and the signal receiving has more error prone. SNR (Signal to Noise Ratio) [7] is defined as:

$$
S N R=\frac{\text { Average power of the signal }}{\text { Average power of the noise in the signal bandwidth }}=\frac{S}{N} \text {. }
$$

Any communication system can be composed of a transmitting end, a channel and a receiving end. In a communication system, for example, if the transmitter signal is $s(t)$, the receiver signal is $r(t)$, the noise is additive white noise $n(t)$, then the received signal can be expressed as:

$$
r(t)=\mathrm{As}(t)+n(t), \quad 0 \leqslant \mathrm{~A} \leqslant 1
$$

In the formula, $\mathrm{A}$ is the signal attenuation caused by the channel. 
It can be seen from the above, if the transmitter signal power is Es, the noise power is En, the SNR of the transmitter can be expressed as Es/En.

Receiver signal power Er can be expressed as:

$$
E r=\mathrm{A}^{2} E s \text {. }
$$

The receiver SNR is $A^{2} E s$, the SNR power change of the receiver relative to the transmitter is channel attenuation.

Therefore, in a communication system, accounting for all gain and attenuation in the transmitter, channel and receiver, can estimate the link margin of signal between the transmitter and the receiver, thus judge whether the signal transmission is successfully.

In summary, according to the wireless communication link estimation process, high-speed data transmission is modeled as follows:

$$
M=T-L
$$

In the formula, $M$ for link margin, $T$ for the attenuation value that receiver allows, $L$ for attenuation value of different parts of the link.

$$
T=20 \lg \left(U_{H} / U_{L}\right) \text {. }
$$

In the formula, $U_{H}$ is the typical value of the output interface signal, and the $U_{L}$ is the lowest threshold of the input interface signal. The calculation formula represents the maximum value of the signal energy attenuation.

\section{B. The Evaluation Method of High-speed Data Long-line Transmission}

In the data transmission link, especially the field of aerospace, high-speed and accurate signal transmission is required. It requires high of high-speed data long-line transmission's reliability [11]. So evaluating the quality of high-speed data long-line transmission links is of great significance. It can be better to solve the problem by comprehensive evaluation of bit error rate and link margin.

The signal by high-speed data long-line transmission is binary digital signal, when the sender sends "1", the receiver receives "0", or the sender to send " 0 ", the receiver receives "1", which is called "bit error". Bit error rate is the probability of the occurrence of bit error [8]. In the process of high-speed data long-line transmission, the BER (Bit Error Rate) is random and inevitable. In the process of testing bit error rate, the test case in a single period cannot explain the problem, therefore, we establish the BER calculation method of highspeed data transmission link [9], [10] as follow, this method considers the factors of the number of tests.

$$
R=\frac{\sum_{\mathrm{i}=1}^{\mathrm{n}} W}{\sum_{\mathrm{i}=1}^{\mathrm{n}} D}
$$

In the formula, $R$ is the link bit error rate, $W$ is the number of bit error for each test, $D$ is the code number for each test, and $\mathrm{n}$ is the number of bit error rate test.

In theory, the BER and the number of test times should be infinite, in order to ensure the accuracy of the bit error rate. But in fact, the BER test can only be carried on in limited times and with finite code number. The BER test result is good, cannot explain the following errors occur is expected to be small.

The essence of link margin is the level of the SNR of the data transmission system, the higher the link margin, the better SNR, the ability to resist noise is stronger and the "expectation" of BER is lower.

In summary, evaluation matrix is established as follows, matrix evaluation mainly consists of two indicators comprehensive, and classified.

- Link bit error rate R.

- Link margin M.

Matrix evaluation method is shown in table I.

TABLE I. MATRIX EVALUATION METHOD

\begin{tabular}{|l|l|l|}
\hline \multicolumn{1}{|c|}{ project } & \multicolumn{1}{c|}{$\begin{array}{c}\text { Meet the link } \\
\text { margin M }\end{array}$} & \multicolumn{1}{c|}{$\begin{array}{c}\text { Do not meet the link } \\
\text { margin M }\end{array}$} \\
\hline $\begin{array}{l}\text { Meet the link } \\
\text { BER R }\end{array}$ & Level A & Level B \\
\hline $\begin{array}{l}\text { Do not meet the } \\
\text { link BER R }\end{array}$ & Level C & Level D \\
\hline
\end{tabular}

- Level A indicates that both the link error rate and link margin are satisfied with the conformity index, and the link design results are good.

- Level B indicates that the link BER meets the qualified index, and the link margin does not meet the qualified index. Link design results are in general, the corresponding measures usually using low loss cable and reducing the number of connector, etc.

- Level C indicates that the link BER does not meet the qualified index, and the link margin meets the qualified index. Link design results are in general, the corresponding measures are usually increasing the parity bit, repeatedly sending and other methods.

- Level D indicates that neither the link error rate nor link margin is satisfied with the qualified index, nor the link design is poor, which is not suitable for application.

- To assess a project, the assessment process as shown in figure 1, firstly, set the link margin and the link bit error rate qualified index, for the following to determine whether indicators satisfied, and then calculate the link margin and the link BER, at last, put the results into the matrix to evaluate. 


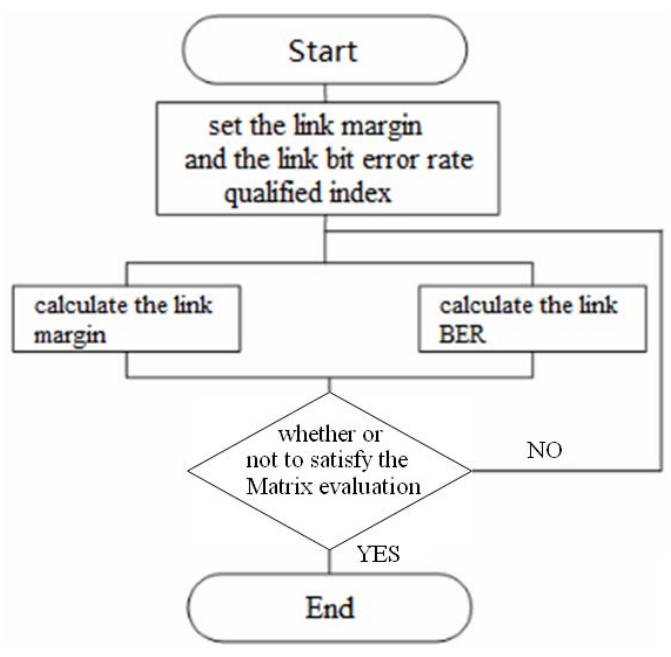

FIGURE I. SCHEMATIC DIAGRAM OF EVALUATION PROCESS

\section{EXPERIMENT RESULTS AND ANALYSIS}

A. Experiment Results and Analysis

High-speed data long-line transmission link consists of controller, cable, connector, test bench, as follows:

- The controller is a high-speed data transmitting end, exchange information with the test bench.

- Cable is a data transmission path between devices, and the length of the cable can be adjusted.

- Connectors are used for the two section of the cable connection; the number of connectors can be adjusted.

- Test bench is used for the operation of the controller to send data as well as to receive data that the controller sends, and count the number of bit error.

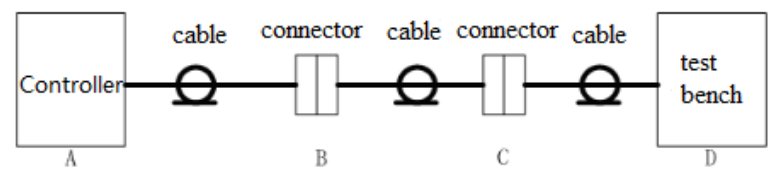

FIGURE II. SKETCH MAP OF HIGH-SPEED DATA LONG-LINE TRANSMISSION LINK

The data transmission rate between the controller and the test bench is $200 \mathrm{Mbps}$, the interface is HOTLINK interface, and the interface circuit schematic diagram is shown in Figure III.

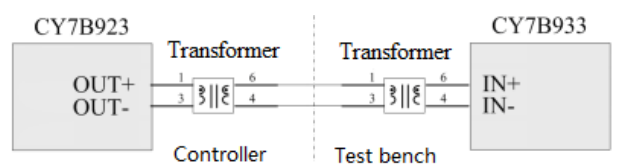

FIGURE III. THE INTERFACE CIRCUIT SCHEMATIC DIAGRAM

The HOTLINK interface is the differential PECL level, as shown in Figure 4, the voltage difference VODIF typical value is $800 \mathrm{mV}$, the minimum voltage difference VIDIF that the input can receive $50 \mathrm{mV}$.

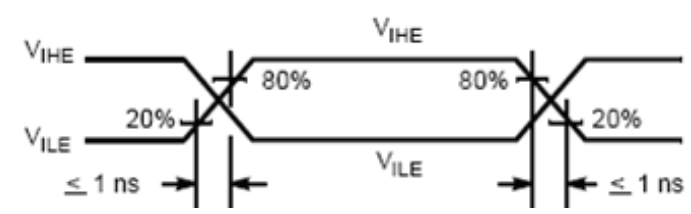

FIGURE IV. HOTLINK SIGNAL LEVEL CHARACTERISTICS

The connecting cable we select is coaxial cable, and the signal attenuation characteristic is shown in Table II.

TABLE II. ATtENUATION CHARACTERISTIC

\begin{tabular}{|c|c|c|c|}
\hline $\begin{array}{c}\text { Erequency } \\
\text { Type }\end{array}$ & $30 \mathrm{MHz}$ & $\mathbf{2 0 0 \mathrm { MHz }}$ & $\mathbf{3 0 0 0 \mathrm { MHz }}$ \\
\hline SFF-50-1.5-1 & $\leqslant 0.19 \mathrm{~dB} / \mathrm{m}$ & $\leqslant 0.50 \mathrm{~dB} / \mathrm{m}$ & $\leqslant 2.0 \mathrm{~dB} / \mathrm{m}$ \\
\hline
\end{tabular}

The connector is a high frequency connector, and the attenuation characteristic is $0.30 \mathrm{~dB} / \mathrm{m}$.

\section{B. Calculation of High-speed Data Long-line Transmission Link Model}

The calculation of high-speed data long-line transmission link model has been taken in three cases that total cable length is $30 \mathrm{~m}, 40 \mathrm{~m}$ and $50 \mathrm{~m}$. The calculation is in the table below.

\section{TABLE III. LINK MODEL MALCULATION LIST}

\begin{tabular}{|l|l|l|l|}
\hline \multicolumn{1}{|c|}{ Project } & \multicolumn{1}{|c|}{ Link 1 } & \multicolumn{1}{|c|}{ Link 2 } & \multicolumn{1}{c|}{ Link 3 } \\
\hline Total cable length & $30 \mathrm{~m}$ & $40 \mathrm{~m}$ & $50 \mathrm{~m}$ \\
\hline Cable attenuation & $15 \mathrm{~dB}$ & $20 \mathrm{~dB}$ & $25 \mathrm{~dB}$ \\
\hline The number of connector pair & 4 pair & 4 pair & 4 pair \\
\hline Connector attenuation & $1.2 \mathrm{~dB}$ & $1.2 \mathrm{~dB}$ & $1.2 \mathrm{~dB}$ \\
\hline Receiver allowed attenuation value T & $24.08 \mathrm{~dB}$ & $24.08 \mathrm{~dB}$ & $24.08 \mathrm{~dB}$ \\
\hline Link margin M & $7.88 \mathrm{~dB}$ & $2.88 \mathrm{~dB}$ & $-2.12 \mathrm{~dB}$ \\
\hline
\end{tabular}

\section{High-speed Data Long-line Transmission Link Test}

High-speed data long-line transmission link test test 3 times for each link, each code number is 32Gbit, test results as shown in table IV. As seen from the table, the link margin calculation of the link 1 and link 2 is greater than 0 , in the test, the error rate is small, and with little difference. Link 3 link margin calculation is less than 0 , in the test, normal communication cannot be realized. The test results are consistent with the calculation results of the model.

TABLE IV. THE SITUATION OF LINK TEST

\begin{tabular}{|l|l|l|l|}
\hline \multicolumn{1}{|c|}{ Project } & \multicolumn{1}{c|}{ Link 1 } & \multicolumn{1}{c|}{ Link 2 } & \multicolumn{1}{c|}{ Link 3 } \\
\hline Test times & 3 times & 3 times & 3 times \\
\hline Test code number & $32 \mathrm{Gbit}$ & $32 \mathrm{Gbit}$ & $32 \mathrm{Gbit}$ \\
\hline Bit error number & 1 & 9 & Unable to communicate \\
\hline BER & $4 \times 10^{-11}$ & $3 \times 10^{-10}$ & - \\
\hline
\end{tabular}

\section{LinK EVALUATION AND RESULt ANALYSIS}

Based on the matrix evaluation method to assess the three links, the situation of assessment as shown in table v. It can be seen from the table that link 1 rating is Level $A$, which has high reliability. Link 2 rating is Level B, although the data transmission can be carried out, but the expectation of the link bit error to occur relatively larger than the 1 link, with the environment changing and link margin being further reduced, 
the BER may be significantly increased. Link 3 rating is Level $\mathrm{D}$, the link cannot establish normal communication.

TABLE V. THE SITUATION OF ASSESSMENT

\begin{tabular}{|l|l|l|l|}
\hline \multicolumn{1}{|c|}{ Project } & \multicolumn{1}{c|}{ Link 1 } & \multicolumn{1}{c|}{ Link 2 } & \multicolumn{1}{c|}{ Link 3 } \\
\hline Set the link margin qualified index & $6 \mathrm{~dB}$ & $6 \mathrm{~dB}$ & $6 \mathrm{~dB}$ \\
\hline Link margin satisfaction & Satisfied & Dissatisfied & Dissatisfied \\
\hline Set the link BER qualified index & $10^{-7}$ & $10^{-7}$ & $10^{-7}$ \\
\hline BER satisfaction & Satisfied & Satisfied & Dissatisfied \\
\hline Assessment result & Level A & Level B & Level D \\
\hline
\end{tabular}

\section{CONCLUSIONS}

This paper presents a high-speed data long-line transmission modeling method and matrix evaluation method. By setting up the test link, the data transmission of the three cases is measured, the link model is verified, and the link evaluation is completed. The theoretical basis is established for the subsequent design of high-speed data long-line transmission link.

\section{REFERENCES}

[1] Jai Narayan Tripathi. Robust Optimization of Serial Link System for Signal Integrity and Power Integrity. Networked Embedded Systems for Enterprise Applications[J], IEEE,2010,52(2):2-8.

[2] Howard W. Johnson, Martin Graham. High-Speed Digital Design: A Handbook of Black Magic[J]. Prentice Hall, 1993.

[3] Louis R. Szabo. Digital memory telemeters for artillery projectiles [C]. Proceedings of International telemetering conference, 1987.

[4] Bogatin, Eric. Signal and Power Integrity-Simplified Second Editon[M].United States on recycled paper at Edwards Brothers in Ann Arbor, Michigan. First printing, July 2009, 44-78.

[5] May M.P, Taove A, Baron J. FDTD Modeling of Digital Propagation in 3-D Circuits with Passive and Active Load[J]. IEEE Transactions on MMT, 1994.

[6] Brian Yong. Digital Signal Integrity: Modeling and Simulation With Interconnects and Package[J]. Prentice Hall, 2000.

[7] Marvin K.Simon,and Samuel Dolinar.Autonomous Software-Defined Radio Receivers for Deep Space Applications(JPL Deep-Space Communications and Navigation Series)[M],2006, chapter 6 Signal-toNoise Ratio Estimation:121-192.

[8] LONG Hai-nan, WANG Miao-miao, ZHAO Jian-zhong. Design of Bit Error R ate Tester Based on DS2172[J]. External Electronic Element, 2007(10):13-16.

[9] [9]Ilias Trachanas, Norbert J. Fliege. A Novel Phase Based SNR Estimation Method for Constant Modulus Constellations[C]. ISCCSP 2008, 1179-1183.

[10] Ahmed M Almradi. Signal to Noise Ratio Estimation using the Expectation Maximization Algorithm[D], Kate Gleason College of Engineering, Rochester Institute of Technology Rochester, New York. 2012.

[11] Kim K, Park K S. Phased-Mission System Reliability Under Markov Environment[J]. IEEE Transactions on Reliability. 1994. 43(2): 301-309. 